Research Article

\title{
Antioxidant Activity of Potato Seedlings at Different Storage Temperatures
}

\author{
Lei Wang $\mathbb{D}^{1,2}$ Junlian Zhang, ${ }^{1}$ Chang Liu, ${ }^{2}$ and Arash Arabmarkadeh ${ }^{3,4}$ \\ ${ }^{1}$ College of Horticulture, Gansu Agricultural University, Lanzhou 730070, China \\ ${ }^{2}$ Dryland Agricultural Research Center, Hebei North University, Zhangjiakou 075000, China \\ ${ }^{3}$ Biotechnology Group, Faculty of Chemical Engineering, Tarbiat Modares University, P.O. Box 14115-143, Tehran, Iran \\ ${ }^{4}$ Microbial Biotechnology Department, Agricultural Biotechnology Research Institute of Iran (ABRII), \\ Agricultural Research Education and Extension Organization (AREEO), Karaj, Iran
}

Correspondence should be addressed to Lei Wang; 5300wanglei@163.com and Arash Arabmarkadeh; arash.arabmarkade@ modares.ac.ir

Received 20 January 2021; Revised 9 February 2021; Accepted 18 February 2021; Published 26 February 2021

Academic Editor: Alireza Baghban

Copyright (c) 2021 Lei Wang et al. This is an open access article distributed under the Creative Commons Attribution License, which permits unrestricted use, distribution, and reproduction in any medium, provided the original work is properly cited.

In order to promote the storage and growth of potato seedlings, the antioxidant activities of potato seedlings at different storage temperatures were analyzed. The antioxidant activities of potato seedlings at two different temperatures were compared. In addition, the effects of high temperature and normal temperature on the growth phenotype and antioxidant system physiological indexes of potato seedlings were analyzed by high temperature treatment. According to the significant change characteristics of SOD activity of antioxidant index at different temperatures, the SOD genes of potato were screened and bioinformatics analysis and gene expression analysis were carried out. The results showed that high temperature inhibited the antioxidant activity of potato seedlings and affected the growth of potato seedlings. The growth of potato seedlings can be promoted in medium and low temperature environment. In the future research, the experimental results can be used as the theoretical basis for potato planting.

\section{Introduction}

Potato is an annual herb tuber plant, which is the fourth largest food crop and the largest non-cereal food crop in the world. It is widely planted in more than 150 countries and regions in the world [1]. Potato has attracted worldwide attention because of its high yield, ecological adaptability, high economic benefit, and rich nutrition. It is an important food crop and economic crop suitable for grain, vegetable, and industrial raw materials. Therefore, potato has promoted the development of world economy and played an important role in strengthening world food security and reducing poverty to a great effect [2]. With the increasing demand for potato vegetables, farmers began to plant potatoes in winter, which not only increased the utilization rate of idle fields in southern China in winter and increased the planting area of potatoes, but also further increased the economic income of farmer s, increased the enthusiasm of farmers for potato planting, and stimulated the development of the industry from production to processing to consumption.

Bad environment will affect the growth and development of plants; one of the most serious environmental factors is temperature. The growth and development of plants at different stages (germination stage, seedling stage, vegetative growth stage, and reproductive growth stage) are affected by high temperature. In the germination stage, the germination rate, germination potential, germination index, and vigor index were significantly reduced under high temperature, and the growth of root system was also significantly inhibited; in the seedling stage, the seedlings were extremely prone to overgrowth, and even withered and died in severe cases; in the vegetative growth stage, the growth was slow, and the leaves grew short, accompanied by yellowing symptoms; in the reproductive growth stage, high temperature would cause the growth of seedlings to grow slowly, 
and the growth of leaves would be shortened. It directly leads to the shortening of flowering period, the abnormal development of flower organs, and the decrease of pollen quantity and vitality, and the abnormal pollination and fertilization will eventually lead to the decrease of seed setting rate. The temperature of each growth stage of the plant is directly affected. Long-term high temperature or low temperature stress will directly cause plant development and even death. Affected by environmental pollution, the climate is abnormal and changeable, and plants are facing more and more severe challenges.

Plant cell membrane is an intermediate substance between cells and external substances, and its composition is closely related to the environment in which it is located. Therefore, the stimulus of external environmental changes to plants will first be reflected in the plant cell membrane. In terms of high temperature stress, cell membrane is the central part of heat stress and heat resistance, and the stability of cell membrane also reflects the heat resistance of plant itself. Potato is a kind of crop which cannot tolerate the extreme change of temperature. High temperature will seriously inhibit the growth and development of potato. Potato will produce many abnormal phenomena after high temperature stress, such as leaf wilting, stem drying, fresh fruit burning, and so on. Once the damage is formed, the plant will be difficult to recover, and will seriously affect the yield. Potato is a cold loving crop with weak tolerance to low temperature. Frost will seriously damage potato plants and lead to yield reduction. High temperature will also seriously inhibit the growth and development of plants. Generally, if the temperature is higher than $26^{\circ} \mathrm{C}$, the potato tubers will stop growing, and higher temperature will even cause damage to the plant.

Plants living in the natural environment are often oppressed by environmental changes, resulting in damage, which is usually closely related to the production and accumulation of oxygen free radicals [3]. In the face of aerobic stress, plants have formed their own protective mechanisms, including enzymatic antioxidant system and nonenzymatic antioxidant system. Sod is a kind of protein and has a certain catalytic ability. It is composed of metal and protein itself. It exists in all parts of plant roots, stems, and leaves. Because of the different metal ions in its catalytic center, SOD can be divided into different types. Generally, SOD is expressed by $\mathrm{Cu} / \mathrm{Zn} \mathrm{SOD}$ and Fe SOD, and the content is relatively stable. However, only when the medium is short of $\mathrm{Fe}$ or $\mathrm{Mn}$ is added to the medium/when Fe chelating agent was insufficient, Mn SOD began to express [4], and different environmental conditions could cause the differential expression of SOD gene. Most of the research data show that the activity of SOD will increase with the increase of temperature stress. However, when the degree of stress exceeds the range that the plant can bear, the activity of SOD will gradually decrease. When cucumber was exposed to low temperature of $13^{\circ} \mathrm{C}$, the activity of SOD increased with the extension of time, but when it was exposed to chilling injury of $28^{\circ} \mathrm{C}$, the SOD activity immediately showed a downward trend [5]. Similarly, in the face of high temperature stress, the activity of superoxide dismutase (SOD) in kiwi fruit showed an upward trend in the early stage of high temperature treatment. However, under long-term stress, with the increasing degree of stress, its activity showed a downward trend [6].

The main characteristic of plants under stress is the imbalance of active oxygen metabolism. The dynamic balance between the generation and elimination of reactive oxygen species in plants is broken, so reactive oxygen species gradually accumulate in plant cells, thus damaging plant cells, and even death in severe cases [7]. SOD, pod, and cat are the main enzymes for scavenging reactive oxygen species in plants. In adversity, plants can initiate stress response, activate antioxidants, induce antioxidant enzyme activities, effectively reduce membrane lipid peroxidation, and ensure membrane stability [8]. The activities of SOD and cat in grape and Lysimachia were increased first and then decreased after high temperature stress. Although sod is thought to remove $\mathrm{O}^{2-}$ and prevent membrane lipid peroxidation from damaging other components of cells, its protective effect is limited [9]. In the late stage of high temperature stress, when the degree of stress exceeds the tolerance of plants, the active center of enzyme will be damaged, and the structure of enzyme protein or the expression of enzyme protein will be inhibited, which will reduce the enzyme activity. When $\mathrm{SOD}$ scavenges $\mathrm{O}^{2-}$, $\mathrm{H}_{2} \mathrm{O}_{2}$ can produce hydroxyl radicals and singlet molecular oxygen, which will cause great damage to plant cells. $\mathrm{H}_{2} \mathrm{O}_{2}$ is removed by pod and cat, thus reducing the degree of oxidation of unsaturated fatty acids and maintaining the stability and integrity of cell membrane. Among them, SOD is the first line of defense in the enzymatic protection system. Therefore, SOD expression is also used as an important physiological index to measure the heat resistance of plants [10].

In this paper, the effects of high temperature and normal temperature on the growth phenotype and physiological index of the antioxidant system of potato seedlings were analyzed by treating potato plants with high temperature. Compared with the traditional method, it is more stable and safe. According to the significant changes of SOD enzyme activity of antioxidant index under different temperature, the potato SOD further screening, gene and gene expression analysis, and bioinformatics analysis results under the high temperature will help us better understand the influence of the potato plant growth and physiological and biochemical changes under different temperature, and heat resistant genes linked to the preliminary analysis and prediction of potatoes, which will provide some theoretical basis to improve heat resistance potato research.

\section{Analysis of Antioxidant Principle}

Antioxidants can be divided into synthetic antioxidants and natural antioxidants according to their sources. They are used in many foods to prevent rancidity and lipid oxidation. Due to concerns about the potential health hazards of synthetic antioxidants, such as BHA, that are carcinogenic in animal experiments, therefore, the research on finding safe natural antioxidants in plants and the application of antler has been in progress [11]. 
Almost all plants have antioxidant capacity. At present, researches focus on Chinese herbal medicine, spices, vegetables, fruits, plant drinks, and cereals. It has been found that many kinds of fruits have strong antioxidant capacity, such as berries, citrus, kiwi fruit, and so on. Lotus root, potato, tomato, spinach, ginger, green pepper, and other vegetables have strong antioxidant capacity [12]. Wine such as whisky, Japanese rice wine, red wine, and Chinese rice wine have strong antioxidant capacity. The antioxidant capacity of green tea and black tea has been widely studied. The antioxidant active components of some herbs and spice plants, such as red root grass, have been widely studied. For example, rosemary has strong antioxidant potential, which can not only delay the oxidation of oil but also reduce the fading of carotene.

The antioxidant activity of the extracts from wheat and peanut bark was stronger than that of the oil extracted from wheat and peanut bark. Industrial and agricultural waste materials, such as potato subcutaneous residue, grape seed, grape peel residue, apple pomace, etc., are cheap and effective sources of natural antioxidants. Fruits and vegetables can protect the body from oxidative damage by enhancing the activity of antioxidant enzymes. On the one hand, fruits and vegetables can inhibit the oxidase system; on the other hand, they can protect the body from oxidative damage by enhancing the activity of antioxidant enzymes. The free radicals in the organism are in the balance between the enzyme regulated biogenic system and the biological protection system. Phenols in fruits and vegetables can combine with the oxidase, affect its conformation, and inhibit the activity of the enzyme. Moreover, phenolic substances have selective inhibitory effect on the oxidase.

Natural antioxidants are often multifunctional, and the mechanism of antioxidant reaction is diverse and complex, and the antioxidant activity of antioxidants in food or biological system is affected by many factors, so it is unreasonable to use a method to evaluate the antioxidant activity of multifunctional food or biological antioxidants. At present, the commonly used antioxidant activity methods are mainly based on two types: (1) in a specific environment, the antioxidant capacity of the tested substance is evaluated by measuring the oxidation inhibition ability of the sample to the lipid substances in the test system; (2) the antioxidant activity of the tested substance is reflected by the scavenging ability of the sample to the artificially generated free radicals; finally, what method is used to indicate the end of the oxidation induction period is the three elements of antioxidant activity determination. Any change of the three elements will change the results, and even change the antioxidant activity order of each antioxidant. Each method has its own advantages and disadvantages. It is important to choose the suitable determination method for different antioxidants. The specific determination method of antioxidant activity is shown in Table 1.

In the process of this experiment, the appropriate method will be selected according to the above principles to complete the analysis of potato seedlings. In this experiment, FRAP method will be used as the main experimental method. This method takes less time and less money and requires simple equipment. Compared with other methods, ABTS method is fast and simple and has strong correlation with antioxidant biological activity. Therefore, it is widely used in biological samples including serum, fruits and vegetables, and some pure substances.

\section{Experiment}

Potato seedlings were planted at different storage temperatures. The germination rate, plant growth potential, root activity, leaf nitrate reductase activity, chlorophyll content, and relative electrical conductivity of potato seedlings were measured at different temperatures to analyze the mechanism of the effects of different temperatures on the growth of potato seedlings.

3.1. Experimental Materials. The materials used in this experiment were all from the Germplasm Resource Bank of potato crop research institute of an agricultural and forestry university. Among them, Hangyin 1 and Hangyin 2 were introduced from Cornell University, P801 was introduced from Zhejiang Academy of Agricultural Sciences, and Zhongshu 3 was introduced from vegetable and Flower Research Institute of Chinese Academy of Agricultural Sciences. Xiaohuangpi was a local variety of Lin'an. Among them, Hangyin 1, Hangyin 2, and P801 were purple sweet potato genotypes; Zhongshu 3 and xiaohuangpi were yellow potato genotypes. The above materials were planted in the experimental base of potato crop research institute of an agricultural and forestry university (Lin'an). The specific potato seedlings are shown in Figure 1.

The above potato seedlings were used as the samples in this experiment, and the antioxidant activity of the seedlings under different temperatures was compared. The functional characteristics of potato peel polysaccharide are shown in Figure 1 . The solubility diagram showed that the three potato peel polysaccharides had good solubility, and there was no significant difference in the solubility of the three polysaccharides, which were all above $95 \%$. The good solubility of polysaccharides makes them have high potential for practical application. There were significant differences among the three polysaccharides, among which PAL had the strongest oil holding capacity $(7.50$ goil/g).

Polysaccharides with high oil retention ability can maintain the intestinal microenvironment sugar in human body, and have better potential application value in the direction of functional food and medicine. The different oil holding capacity of polysaccharides is related to the structure of polysaccharides. The foaming property (C) and foam stability (D) were investigated. PAL showed the strongest foaming activity (78.5\%) and foam stability (43.2\%).

3.2. Overview of Experimental Site. The experimental site is located in the Houshan cultivation garden of a city university of science and technology $\left(104^{\circ} 42.0302^{\prime} e\right.$ and $\left.31^{\circ} 32.2546^{\prime} n\right)$, belonging to the humid monsoon climate zone of northern subtropical mountain, with distinct seasons, sufficient sunshine, and sufficient rainfall. The altitude is $519 \mathrm{~m}$, the 
TABLE 1: Determination of antioxidant activity in vitro.

\begin{tabular}{|c|c|c|}
\hline $\begin{array}{l}\text { Method } \\
\text { number }\end{array}$ & Method category & Determination content \\
\hline 1 & Fluorescence method & $\begin{array}{l}\text { Oxygen free grave absorption capacity } \\
\text { Total free grave trap antioxidant parameter method }\end{array}$ \\
\hline 2 & $\begin{array}{l}\text { Determination methods involving hydrogen atom } \\
\text { transfer reaction }\end{array}$ & $\begin{array}{l}\text { Experiment on saffron bleaching } \\
\text { Oxygen consumption inhibition test } \\
\text { Inhibition of linoleic acid oxidation } \\
\text { Low-density lipoprotein oxidation inhibition test }\end{array}$ \\
\hline 3 & $\begin{array}{l}\text { Determination methods involving electron transfer } \\
\text { reactions }\end{array}$ & $\begin{array}{c}\text { A note on the parameters of reduction and oxidation resistance of } \\
\text { trivalent iron } \\
\text { 1,1-Diphenyl-2-picrylhydrazine method } \\
\text { Copper reduction } \\
\text { Determination of total phenols by folin phenidine }\end{array}$ \\
\hline 4 & Other determination methods & $\begin{array}{l}\text { Total oxidation removal } \\
\text { Chemiluminescence } \\
\text { Electrochemiluminescence }\end{array}$ \\
\hline
\end{tabular}

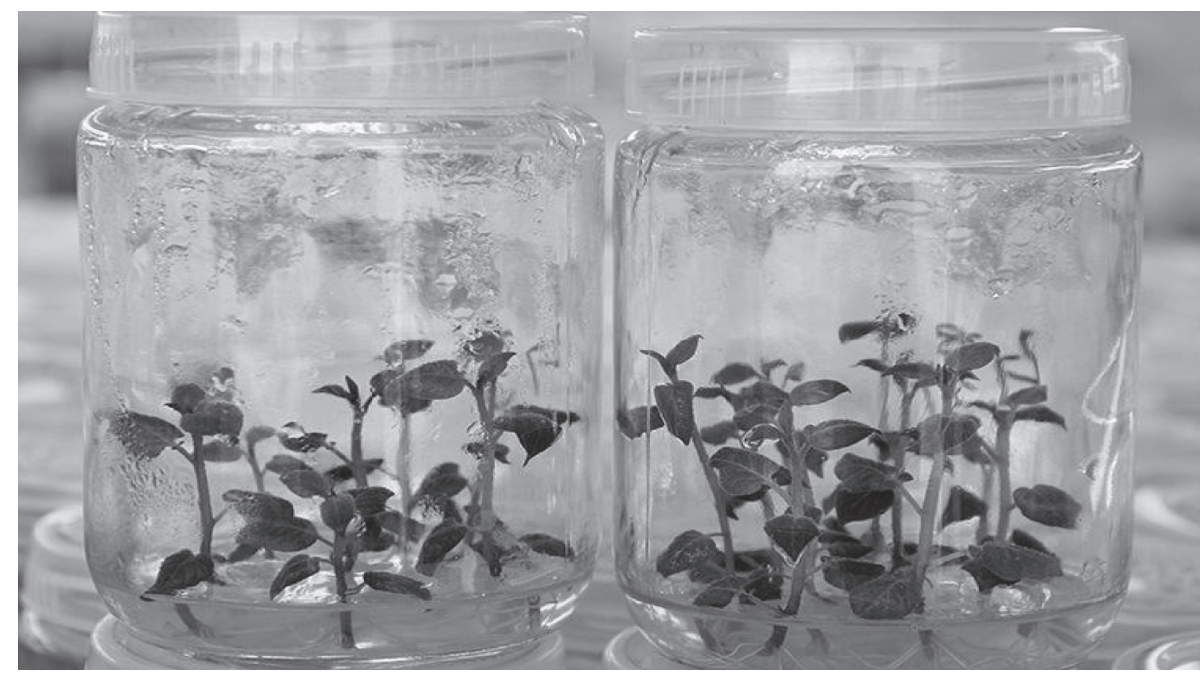

Figure 1: Potato seedling sample.

annual sunshine is $1298.1 \mathrm{~h}$, the frost free period is 272 days, and the rainfall is $963.2 \mathrm{~mm}$. The annual average temperature is $16.3^{\circ} \mathrm{C}$, the average temperature in January is $5.2^{\circ} \mathrm{C}$, the average temperature in July is $26^{\circ} \mathrm{C}$, the extreme minimum temperature is $-4.8^{\circ} \mathrm{C}$, the extreme maximum temperature is $37^{\circ} \mathrm{C}$, the soil type is yellow soil, the organic matter content is $18.99 \%$, and $\mathrm{pH}$ is 6.88 . The terrain of the experimental site is relatively gentle, the site conditions are consistent, the soil layer is fertile, and the irrigation water source is rich. The experiment process of potato seedling was completed here.

\subsection{Experimental Reagents and Equipment. Reagents were as} follows: anhydrous sodium acetate, AR grade reagent, chemical reagent, Guoyao Holding Co., Ltd.; acetic acid, AR grade reagent, Tianjin Guangfu Fine Chemical Research Institute; ethanol, AR grade reagent, Tianjin Guangfu Fine Chemical Research Institute; hydrochloric acid, analytical pure, Tianjin Yongsheng Fine Chemical Co., Ltd.; anhydrous ferric chloride, AR grade reagent, Tianjin Guangfu Fine Chemical Research Institute.

Equipment was as follows: Shanghai Precision Instrument Co., Ltd. WSC-S color difference colorimeter, gel imaging analyzer (PEI Qing JS-680D), ultramicro nucleic acid detector (NanoDrop Lite), PCR instrument (Bio-Rad T100TM Thermal Cycler), fluorescence quantitative PCR (Bio-Rad PCR), cold storage freezer box, Dk-s24 electric constant temperature water bath pot, dz-400 vacuum packaging machine, ar423 CN electronic balance, portable $\mathrm{pH}$ meter, SB25-12DTD ultrasonic cleaning machine.

\subsection{Experimental Methods}

3.4.1. Preparation Before Experiment. The values of Hunter $\mathrm{L}$, $\mathrm{a}$, and $\mathrm{b}$ were determined by wsc-s colorimeter of Shanghai Precision Instrument Co., Ltd, where $\mathrm{L}^{*}$ is the brightness value, $\mathrm{a}^{*}$ is the red degree, and $\mathrm{b} *$ is the yellow degree. $\mathrm{C}^{*}$ is used to indicate the brightness of the color [13]. 
The extinction value method was used. $20 \mathrm{~g}$ of sample was weighed and put into the beater, $200 \mathrm{ml}$ of cold distilled water was added, homogenized for $40 \mathrm{~s}$, the filtrate was kept in a $25^{\circ} \mathrm{C}$ water bath for $5 \mathrm{~min}$, and the absorbance $a$ was determined at $410 \mathrm{~nm}$. The browning degree was expressed as 10 a410.

3.4.2. Set Storage Temperature. The refrigerator was disinfected with $250 \mathrm{ppm}$ chlorine water before the test, and the samples were disinfected with the same concentration of chlorine water. The potato seedlings were washed and soaked in the color protection solution for $15 \mathrm{~min}$, and the water attached to the surface was removed and drained. Then, they were separately packed in polyethylene tray and packed in two layers of polyethylene film. They were stored in refrigerators at $10^{\circ} \mathrm{C}-30^{\circ} \mathrm{C}$ for 7 days. Samples were taken every day. After 7 days, they were placed in $200^{\circ} \mathrm{C}$ environment for one day (the 8 th day). The samples were taken, and then the indexes were determined.

3.4.3. Preparation of Potato Seedling Sample Extract. $1.00 \mathrm{~g}$ potato seedling extract was put into a $50 \mathrm{ml}$ triangular flask, $25 \mathrm{ml}$ of $70 \%$ ethanol solution was added, and then it was extracted in ultrasonic water bath for $30 \mathrm{~min}$ and centrifuged at $6000 \mathrm{r}$ for $15 \mathrm{~min}$, and the supernatant was poured into a $50 \mathrm{ml}$ volumetric flask. The filter residue in the original triangular flask was added with $25 \mathrm{ml}$ of $70 \%$ ethanol solution. After shaking, it was extracted for $30 \mathrm{~min}$ in the ultrasonic water bath (the same as the first extraction), and then $6000 \mathrm{R}$ centrifugation for $15 \mathrm{~min}$. The supernatant was combined twice, and the volume was fixed into a $50 \mathrm{ml}$ volumetric flask with $70 \%$ ethanol solution. The extract was prepared into the corresponding concentration for the determination of total antioxidant capacity and superoxide anion scavenging rate.

3.4.4. Determination of Total Antioxidant Capacity. Reagent preparation: first prepare reagent A: $0.3 \mathrm{~mol} / \mathrm{L}$ sodium acetate buffer solution (first weigh $0.187 \mathrm{~g}$ of anhydrous sodium acetate, then add $1.6 \mathrm{ml}$ acetic acid, and fix the volume with distilled water into a $100 \mathrm{ml}$ volumetric flask for standby).

Preparation of reagent B: take $0.36 \mathrm{ml}$ concentrated hydrochloric acid, dilute it with distilled water to a $100 \mathrm{ml}$ volumetric flask for standby, prepare $40 \mathrm{mmol} / \mathrm{L}$ hydrochloric acid solution, then weigh $0.156 \mathrm{~g}$ of 2.4.6-tripyridyl triazine, and then dissolve 2.4.6-tripyridyl triazine with $40 \mathrm{mmol} / \mathrm{L}$ hydrochloric acid solution, and then fix the volume into a $100 \mathrm{ml}$ volumetric flask to prepare $10 \mathrm{mmol} / \mathrm{L}$ tripyridyl triazine reagent.

Preparation of reagent C: weigh $0.548 \mathrm{~g}$ of ferric chloride, dissolve it in distilled water, fix the volume into a $100 \mathrm{ml}$ volumetric flask, and prepare $20 \mathrm{mmol} / \mathrm{L}$ ferric chloride solution. Determination of oxidation resistance of samples: the sample solution was determined according to the method of making standard curve. With $1.0 \mathrm{mmol} / \mathrm{L} \mathrm{FeSO} 4$ as the standard, the antioxidant activity (FRAP value) of the sample was expressed by the number of millimoles of FeSO 4 required to reach the same absorbance. The specific calculation formula is as follows:

$$
\operatorname{FRAP}=\frac{X * V_{2} * n}{W * V_{1} * 10}
$$

In formula (1), $X$ is set as the concentration value of the sample calculated according to the standard curve ( $\mathrm{mmol} / \mathrm{L})$; $V_{1}$ is set as the sampling volume $(\mathrm{L}) ; V_{2}$ is set as the total volume of sample liquid (L); $W$ is set as the weight of raw material ( $100 \mathrm{~g})$; and $n$ is set as the dilution ratio of the sample.

3.4.5. Determination of Total Phenol Content. Drawing of gallic acid standard curve: accurately weigh $0.005 \mathrm{~g}$ gallic acid, put it into a $50 \mathrm{ml}$ volumetric flask, and fix the volume to $50 \mathrm{ml}$ with distilled water (the mass concentration is $0.1 \mathrm{mg} / \mathrm{ml}$ ). Accurately suck 0.0, 0.1, 0.2, 0.4, 0.6, and $0.8 \mathrm{ml}$ of gallic acid standard solution, put them into $10 \mathrm{ml}$ calibrated test tubes, respectively, add $5 \mathrm{ml}$ of Folin reagent in sequence, and let it stand for $4-8 \mathrm{~min}$, then add $4 \mathrm{ml}$ of $7.5 \%$ $\mathrm{Na}_{2} \mathrm{CO}_{3}$, respectively, and fix the volume to the scale. After reacting for $1 \mathrm{~h}$ at the dark place, take the reaction solution without standard solution as the control, measure the absorbance at $765 \mathrm{~nm}$, take the concentration of gallic acid as the abscissa, and take the absorbance $a$ value as the ordinate to draw the standard curve. Take $1 \mathrm{ml}$ of the prepared sample solution, dilute it 10 times, use $70 \%$ absolute ethanol instead of the sample as blank, determine according to the method of making gallic acid standard curve, and add the following formula to calculate the total phenol content in the sample [14]. The specific formula is as follows:

$$
\mathrm{TAE}=\frac{10 * V_{2} * X}{W * V_{1}} .
$$

In formula (2), TAE is set as the equivalent value of total phenolic gallic acid of the sample $(\mathrm{mg} / \mathrm{g}) ; V_{1}$ is set as the concentration value of the sample converted from the absorbance value $(\mathrm{mg} / \mathrm{ml}) ; V_{2}$ is set as the sampling volume $(\mathrm{ML}) ; X$ is set as the total volume of the sample extract $(\mathrm{ML})$; and $W$ is set as the weight of raw material (g). It is set as the equivalent value of total phenolic gallic acid in the sample (mg/ $\mathrm{g}$ ); it is set as the sample concentration value converted from the absorbance value $(\mathrm{mg} / \mathrm{ml})$; it is set as the sampling volume (ML); it is set as the total volume of the sample extraction solution (ml); it is set as the weight of raw material $(\mathrm{g})$.

\section{Results and Discussion}

4.1. Growth of Potato Seedlings. Potato seedlings have high water activity and $\mathrm{pH}$ value, and cutting treatment can damage the tissue protective layer, and cause nutrient leakage; it is very easy to be contaminated by microorganisms, which makes the quality of potato seedlings decline, and the safety of planting is affected. The results showed that there was no spoilage caused by microbial growth during the first three days of storage at $5^{\circ} \mathrm{C}-15^{\circ} \mathrm{C}$. On the fourth day, the potato seedlings stored at $15^{\circ} \mathrm{C}$ began to brown, and spread from the center to the outside, and the potato seedlings began to soften and rot; on the sixth day, the 
potato seedlings stored at $15^{\circ} \mathrm{C}$ began to rot and grow hair, and the browning was serious; on the seventh day, $90 \%$ of the rot had already occurred. At this time, the fungi on the surface of potato seedlings began to dominate, which caused great harm to human beings. Plant in adversity stress after reaching a certain degree (free radical metabolism in cells balance is destroyed) produces a large number of free radicals, and excess free radicals will cause harm to the cell membrane structure and function, cause the cell membrane lipid peroxidation and membrane lipid peroxidation product malondialdehyde (MDA) to hurt cell membrane structure and function, and increase the electrolyte leakage, leading to cell membrane permeability increased. Zhao Xinnan et al. studied the physiological effects of potassium application on drought resistance of Lanzhou lily and found that potassium application reduced MDA content. The results of this experiment showed that potassium chloride could significantly reduce the MDA content and the increase of relative electrical conductivity of potato leaves under drought stress, indicating that potassium chloride could reduce the lipid peroxidation of potato leaves. However, potato seedlings stored at $5^{\circ} \mathrm{C}$ were not detected. The browning point of potato seedlings stored at $5^{\circ} \mathrm{C}$ for one day (i.e., the 8th day) began to appear. Therefore, in the laboratory determination, the indexes were determined at $15^{\circ} \mathrm{C}$ for 5 days, $5^{\circ} \mathrm{C}$ for 7 days, and $20^{\circ} \mathrm{C}$ for 1 day.

4.2. Color Difference Analysis of Potato Seedlings. $C^{*}$ means color. Color is one of the important parameters of potato seedling health. During storage, the color changes due to water loss, pigment oxidation, and other reasons, affecting its appearance. $L^{*}$ value represents brightness, and the decrease of $L^{*}$ can directly reflect the degree of surface darkening caused by enzymatic browning or pigment aggregation in storage engineering. The lower the $L^{*}$, the more serious the browning. It can be seen from Figure 2 that the change trend of $L^{*}$ value and $C^{*}$ value of potato seedlings during storage is the same, which decreases with the increase of storage time. Compared with the storage at $15^{\circ} \mathrm{C}$, the value of $5^{\circ} \mathrm{C}$ is larger, and the color is more distinct than that at $15^{\circ} \mathrm{C}$. Compared with the storage at $15^{\circ} \mathrm{C}$, the value of $5^{\circ} \mathrm{C}$ is larger, and the color is more distinct than that at $15^{\circ} \mathrm{C}$. In other words, the color changes greatly under the storage condition of $15^{\circ} \mathrm{C}$, which may be caused by more water loss at higher temperature. In addition, at higher temperature, more pigments are oxidized, which may be one of the reasons for the great color change. The value of potato seedlings stored at $5^{\circ} \mathrm{C}$ was higher than that at $15^{\circ} \mathrm{C}$ during the whole storage period, indicating that $5^{\circ} \mathrm{C}$ could maintain the appearance quality of potato seedlings.

4.3. Browning Degree of Potato Seedlings. It can be seen from Figure 3 that, on the 4 th day, the browning degree of potato seedlings stored at $15^{\circ} \mathrm{C}$ began to appear, and spread from the center to the outside of the seedlings, and the potato seedlings began to soften and rot. During the storage period of 1-5 days, the browning degree of potato seedlings stored at $15^{\circ} \mathrm{C}$ increased slowly with the storage time, while the browning

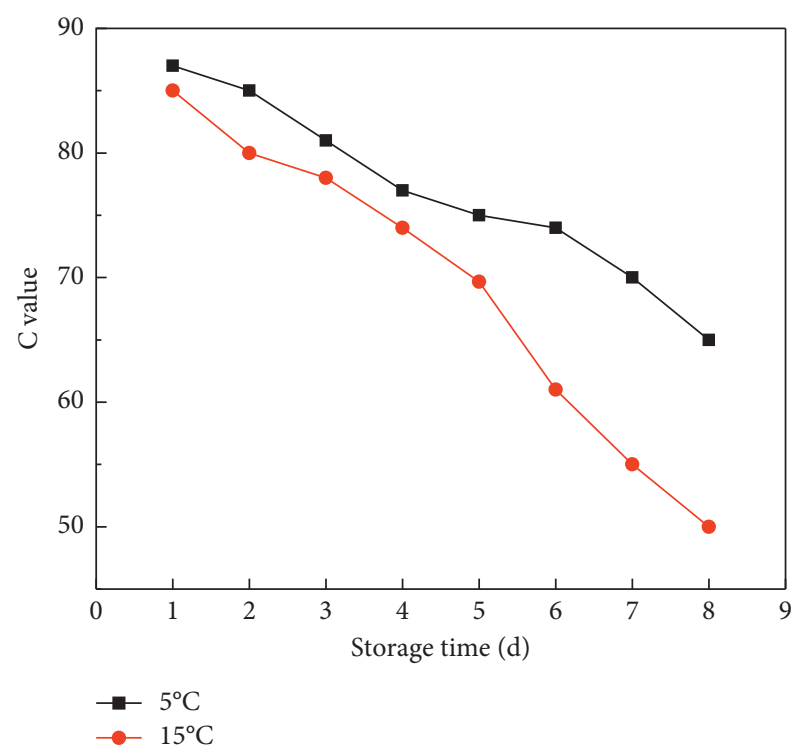

Figure 2: Color difference analysis results of potato seedlings. (a) Color change curve of potato seedlings.

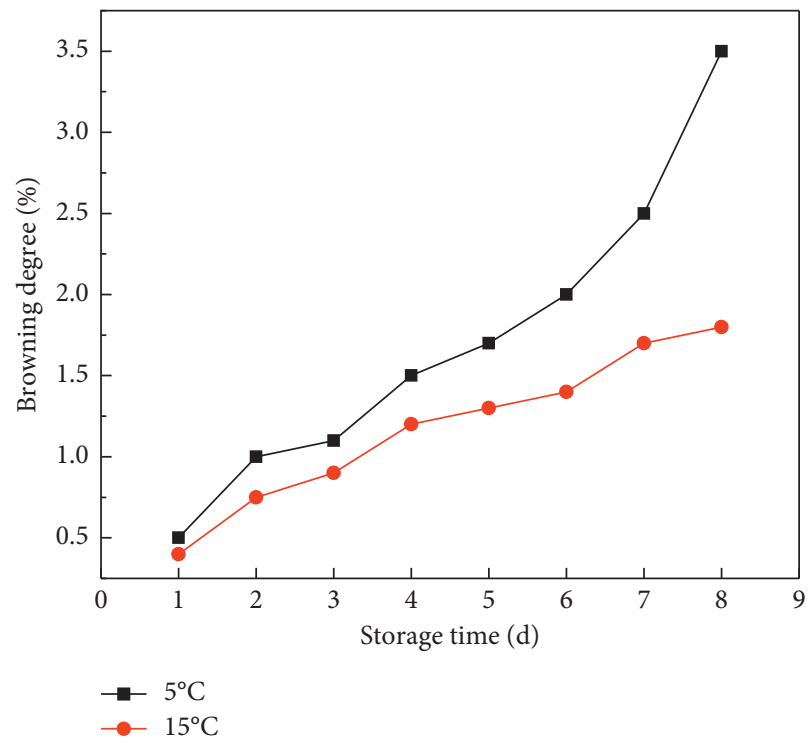

Figure 3: Analysis results of browning degree of potato seedlings.

degree increased rapidly at $5^{\circ} \mathrm{C}(1-3 \mathrm{D})$, and from the $3 \mathrm{rd}$ day, the browning degree of potato seedlings stored at $15^{\circ} \mathrm{C}$ increased slowly. The increase is slow and the change is not big. It began to increase after the 6th day. There was significant difference in browning degree of potato seedlings after the 4 th day. Therefore, it can be considered that storage at $5^{\circ} \mathrm{C}$ can effectively alleviate the browning of potato seedlings.

4.4. Analysis of Total Antioxidant Capacity of Potato Seedlings. Using FRAP method to combine the results of risk assessment into the risk management process to reduce the deviation of threat assessment, the decision principle of risk control measures is introduced according to the result of risk assessment. FRAP method does not reflect the scavenging 
activity of certain free radicals, but the total reduction capacity of samples. Therefore, the results of FRAP method can be used to reflect the total antioxidant activity of samples. The curves of total antioxidant capacity of potato seedlings at different periods in this experiment are shown in Figure 4.

It can be seen from Figure 4 that, in the process of the experiment, the FRAP value of potato seedlings in the environment of $5^{\circ} \mathrm{C}$ was the highest on the first day of the experiment. After that, the FRAP value decreased daily during the experiment. The FRAP value of potato seedlings in $15^{\circ} \mathrm{C}$ environment was slightly lower than that in $5^{\circ} \mathrm{C}$ environment, and its change trend was the same as that of potato seedlings in $5^{\circ} \mathrm{C}$. However, the decreasing trend was larger than that of FRAP value in $5^{\circ} \mathrm{C}$ environment. Therefore, the antioxidant capacity of potato seedlings in $5^{\circ} \mathrm{C}$ environment was ranked as follows: potato seedlings in $5^{\circ} \mathrm{C}$ environment in the first day, potato seedling experiment in $15^{\circ} \mathrm{C}$ environment in the middle stage, and potato seedling experiment in $15^{\circ} \mathrm{C}$ environment in the end. In conclusion, the antioxidant capacity of potato seedlings at $5^{\circ} \mathrm{C}$ was stronger.

4.5. Analysis of Total Phenol Content in Potato Seedlings. Polyphenols are common antioxidants in fruits and vegetables. Under the same treatment conditions, the contents of antioxidant components in different varieties are significantly different. The total phenol content of potato seedlings in this experiment was determined as shown in Figure 5.

It can be seen from Figure 5 that the total phenol content of potato seedlings at $5^{\circ} \mathrm{C}$ is higher. In the use of the experiment, due to the change of storage environment, there will be a corresponding loss of total phenol content. The order of total phenol content in use can be expressed as follows: potato seedling in $5^{\circ} \mathrm{C}$ environment on the first day, potato seedling experiment in $15^{\circ} \mathrm{C}$ environment on the first day, potato seedling experiment in $5^{\circ} \mathrm{C}$ environment in middle stage, potato seedling experiment in $15^{\circ} \mathrm{C}$ environment at $5^{\circ} \mathrm{C}$ end of potato seedling experiment in $15^{\circ} \mathrm{C}$ environment on the first day. According to the data, the total phenol content of potato seedlings in $5^{\circ} \mathrm{C}$ environment was higher.

4.6. Analysis of Physical and Chemical Properties of SOD Gene in Potato. After analysis, the physicochemical properties of potato SOD gene are shown in Table 2, and the protein length is different, $\mathrm{Cu} / \mathrm{Zn}$. The results showed that the shortest SOD2 was 167 amino acids, and the longest SOD1 was 309 amino acids; the molecular weight ranged from $16834.23 \mathrm{da}$ to 34495.16da; the isoelectric points of Fe-SOD3 and Fe-SOD4 were 5.51 and 5.93, Mn SOD was 7.09, and the other SOD gene isoelectric points were between 6.0 and 7.0; the instability index showed that the stability of potato SOD gene proteins was poor; these proteins were hydrophilic eggs white.

4.7. Prediction of Phosphorylation Sites of SOD Gene in Potato. Protein phosphorylation refers to the transfer of phosphate groups on ATP or Gity sites to amino acid residues of substrate proteins catalyzed by protein kinases. It is a basic

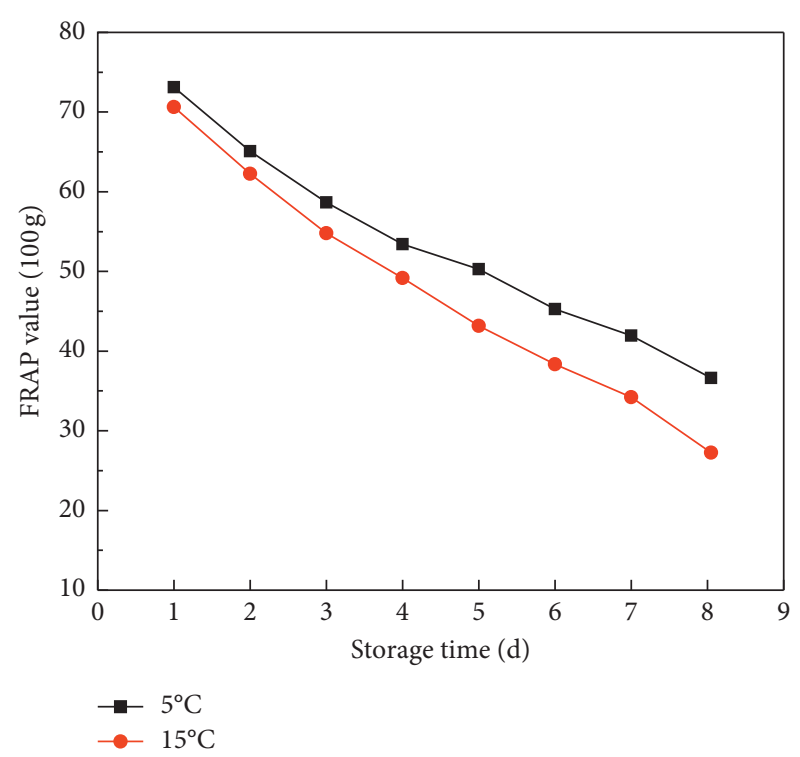

Figure 4: Analysis results of total antioxidant capacity of potato seedlings.

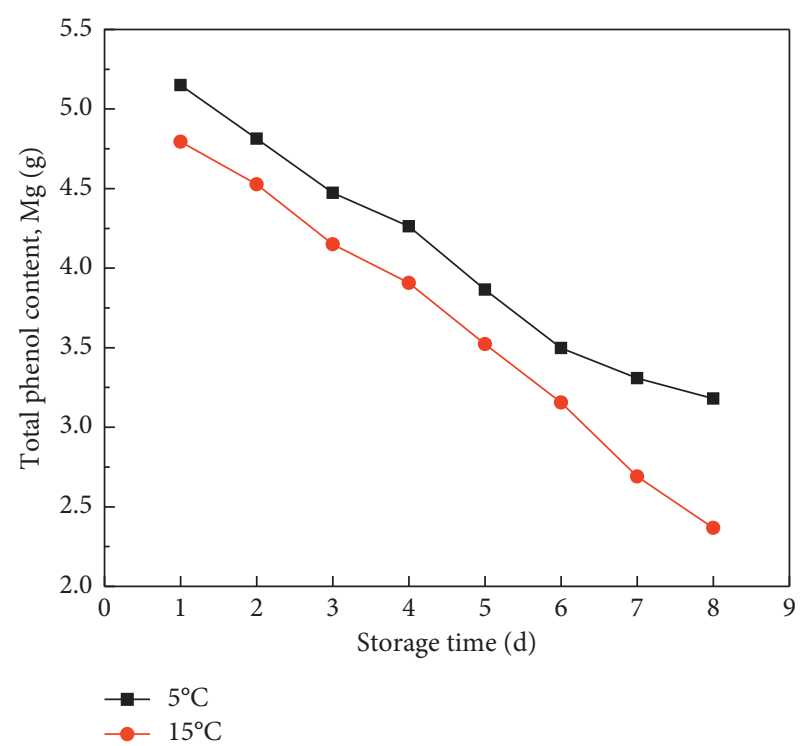

FIGURE 5: Analysis results of total phenol content in potato seedlings.

and common regulation mode in organisms. The phosphorylation sites of potato SOD gene were predicted in this experiment, as shown in Table 3. SOD1 has the most potential phosphorylation sites, a total of 45 , which contains 28 serine, 17 threonine, and only one tyrosine; $\mathrm{Cu} / \mathrm{Zn}$ SOD1 has the least potential phosphorylation sites, a total of 13 , including 10 serine, 3 threonine, and no tyrosine.

4.8. Expression Analysis of SOD in Potato under High Temperature. The expression of SOD gene in potato under high temperature is shown in Figure 6. In this experiment, all SOD genes are expressed in potato leaves, and the expression of different genes is different under high temperature stress. 
TABLe 2: Physiial and chemical properties of potato SOD genes.

\begin{tabular}{|c|c|c|c|c|c|c|c|}
\hline $\begin{array}{l}\text { Protein } \\
\text { name }\end{array}$ & $\begin{array}{l}\text { Protein length } \\
\text { (aa) }\end{array}$ & $\mathrm{Mw}(\mathrm{Da})$ & PI & $\begin{array}{c}\text { Residue numbers of the } \\
\text { positive charge }\end{array}$ & $\begin{array}{l}\text { Residue numbers of the } \\
\text { negative charge }\end{array}$ & $\begin{array}{l}\text { Instability } \\
\text { index }\end{array}$ & $\begin{array}{l}\text { Hydrophilic } \\
\text { value }\end{array}$ \\
\hline SOD1 & 309 & 33078 & 6.03 & 31 & 33 & 35.89 & -0.045 \\
\hline $\begin{array}{l}\mathrm{Cu} / \mathrm{Zn} \\
\text { SOD1 }\end{array}$ & 167 & 16834.23 & 6.87 & 14 & 15 & 18.76 & -0.138 \\
\hline $\begin{array}{l}\mathrm{Cu} / \mathrm{Zn} \\
\mathrm{SOD} 2\end{array}$ & 215 & 22221.75 & 6.35 & 11 & 14 & 26.61 & -0.021 \\
\hline Fe-SOD1 & 258 & 29559.12 & 6.12 & 26 & 27 & 42.57 & -0.248 \\
\hline $\mathrm{Fe}-\mathrm{SOD} 2$ & 251 & 28323.24 & 6.67 & 25 & 28 & 34.59 & -0.479 \\
\hline $\mathrm{Fe}-\mathrm{SOD} 3$ & 304 & 34495.16 & 5.51 & 32 & 41 & 40.58 & -0.532 \\
\hline $\mathrm{Fe}-\mathrm{SOD} 4$ & 214 & 23808.13 & 5.93 & 21 & 24 & 31.87 & -0.418 \\
\hline $\mathrm{Mn}-\mathrm{SOD}$ & 231 & 25331.57 & 7.09 & 22 & 22 & 35.54 & -0.315 \\
\hline
\end{tabular}

Table 3: Prediction of phosphorylation sites of the potato SOD genes.

\begin{tabular}{|c|c|c|c|c|}
\hline \multirow{2}{*}{ Protein name } & \multicolumn{4}{|c|}{ The numbers of potential phosphorylation site } \\
\hline & Serine & Threonine & Tyrosine & Total number \\
\hline SOD1 & 27 & 17 & 1 & 45 \\
\hline $\mathrm{Cu} / \mathrm{Zn}$ SOD1 & 10 & 3 & 0 & 13 \\
\hline $\mathrm{Cu} / \mathrm{Zn} \mathrm{SOD} 2$ & 15 & 15 & 2 & 32 \\
\hline Fe-SOD1 & 20 & 9 & 4 & 33 \\
\hline $\mathrm{Fe}-\mathrm{SOD} 2$ & 18 & 12 & 3 & 33 \\
\hline $\mathrm{Fe}-\mathrm{SOD} 3$ & 10 & 12 & 6 & 28 \\
\hline $\mathrm{Fe}-\mathrm{SOD} 4$ & 8 & 4 & 4 & 16 \\
\hline Mn-SOD & 9 & 6 & 4 & 19 \\
\hline
\end{tabular}

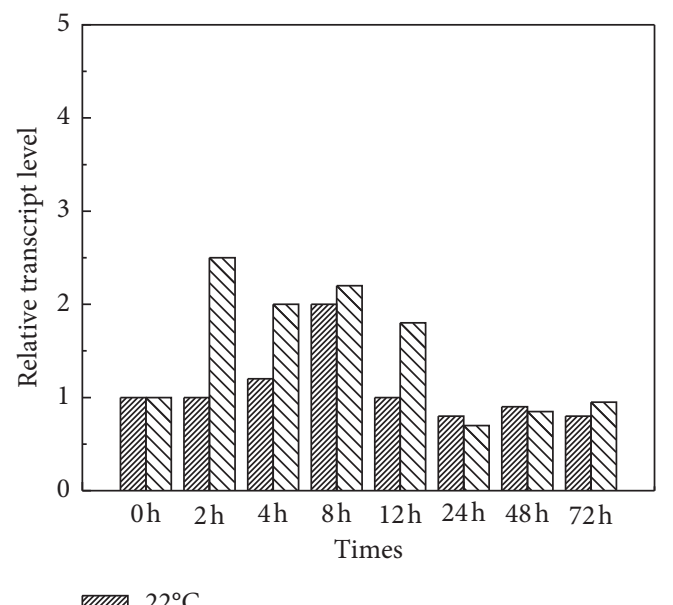

$22^{\circ} \mathrm{C}$

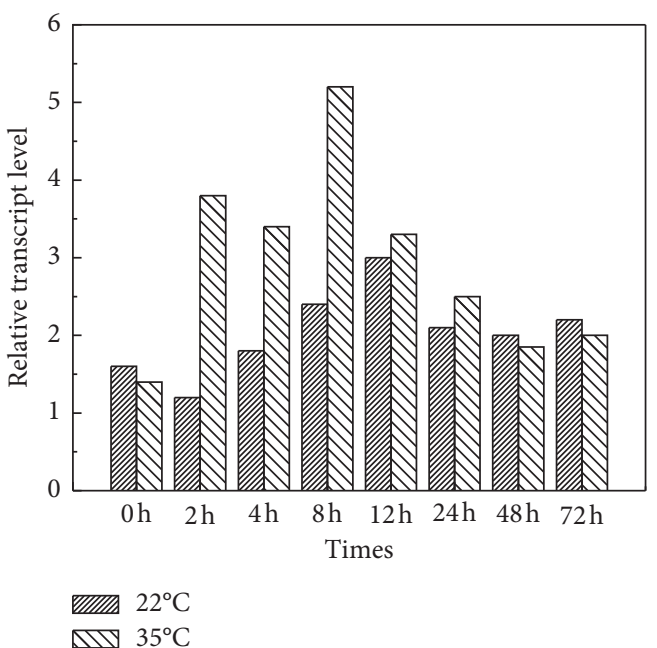

(b)

Figure 6: Continued. 

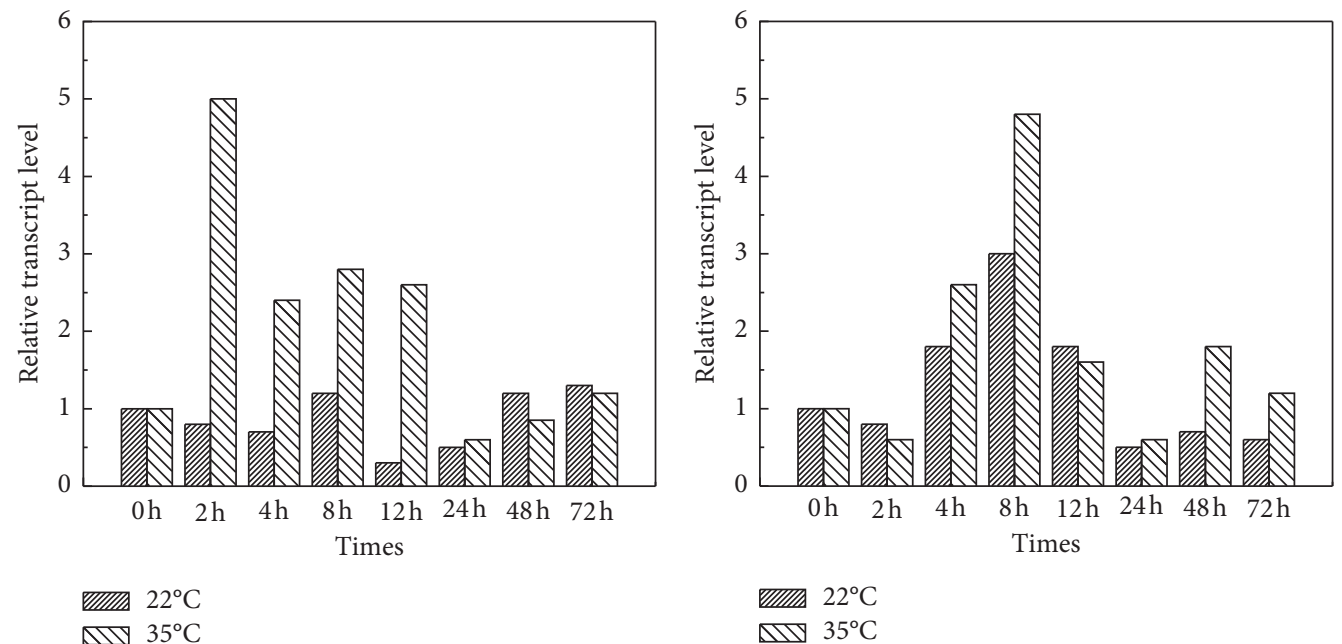

(c)

(d)
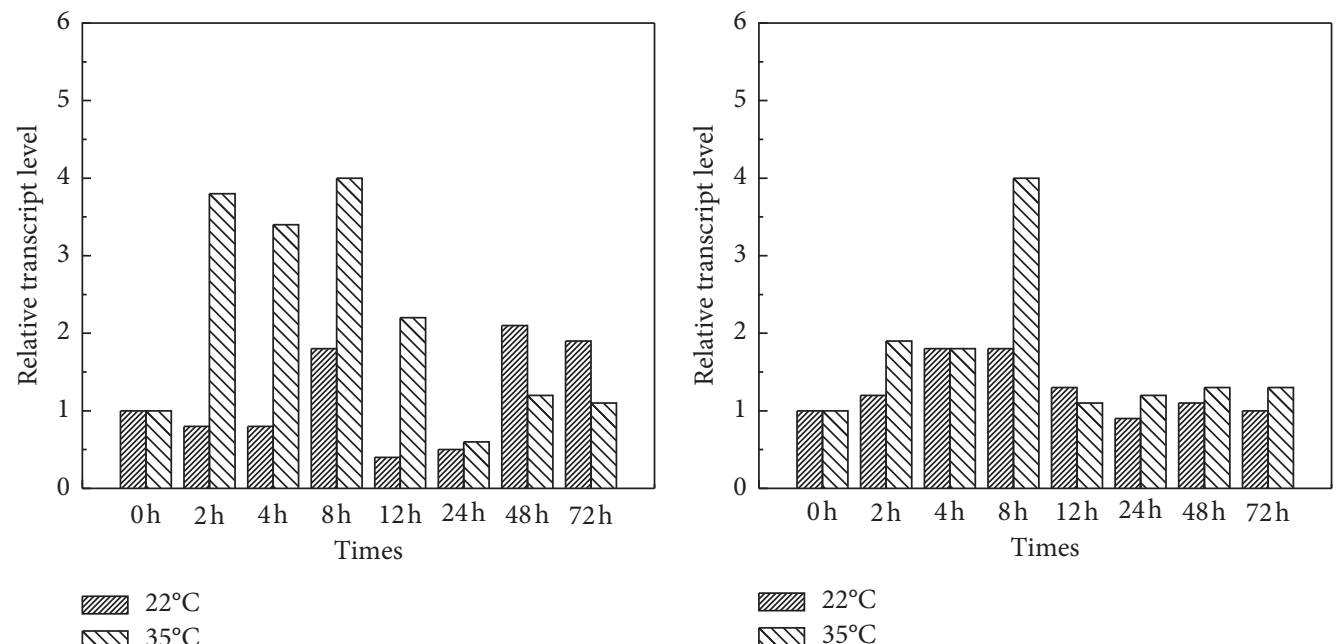

(e)

(f)

FIGURE 6: Effect of high temperature stress on SOD gene expression in potato. (a) SOD1. (b) Fe-SOD1. (c) Fe-SOD2. (d) Fe-SOD3. (e) FeSOD4. (f) $\mathrm{Cu}-\mathrm{Zn}-\mathrm{SOD} 1$.

In the early stage of high temperature, the expression level increased, especially at $2 \mathrm{~h}$, which was about 2.5 times higher than that under normal temperature. However, after $24 \mathrm{~h}$, the expression level was not significantly different from that under normal temperature.

The expression levels of Fe-SOD1, Fe-SOD2, Fe-SOD3, and Fe-SOD4 increased at high temperature. The expression level of Fe-SOD1 reached the peak at $8 \mathrm{~h}$, which was 2.3 times higher than that at room temperature. The expression level of Fe-SOD2 reached the peak at $2 \mathrm{~h}, 6.47$ times higher than that at room temperature, and reached the peak at $8 \mathrm{~h}$, 1.60 and 2.29 times that at room temperature, respectively. The expression levels of Fe-SOD1, Fe-SOD2, and Fe-SOD4 increased significantly in the early stage of high temperature, but were inhibited after $48 \mathrm{~h}$, while the expression level of FeSOD3 was still higher than that at room temperature in the later stage. The expression of $\mathrm{Cu} / \mathrm{Zn} \mathrm{SOD} 1, \mathrm{Cu} / \mathrm{Zn}$ SOD2, and Mn SOD did not change significantly. The expression of
$\mathrm{Cu} / \mathrm{Zn} \mathrm{SOD} 2$ at room temperature was 2.22 times higher than that at high temperature at $12 \mathrm{~h}$ in Figure 6.

\section{Conclusion}

To study the effects of different storage temperatures on the antioxidant activity of potato seedlings, the innovation lies in completing the main experimental process through the determination of physiological indexes, including growth morphology indexes, antioxidant indexes, and photosynthetic indexes. Growth morphological indicators included plant height, stem diameter, leaf length, leaf width, leaf fresh weight, and dry matter weight. The results showed that the color and brightness of potato seedlings could be inhibited by temperature, and the length and width of potato leaves were significantly less than those under normal temperature. The fresh weight and dry weight of leaves continued to decrease with high temperature, indicating that high 
temperature could significantly affect the growth and inhibit the growth of potato.

Through this study, it can be determined that different storage temperatures have an effect on the antioxidant activity of potato seedlings. When the temperature was too high, the antioxidant activity of potato seedlings was destroyed. High temperature inhibited the antioxidant activity of potato seedlings. The water content of potato seedlings decreased gradually, and brightness and freshness decreased during storage. However, compared with $15^{\circ} \mathrm{C}$, potato seedlings stored at $5^{\circ} \mathrm{C}$ maintained better apparent quality. The results showed that the total phenols and antioxidant capacity of potato seedlings increased during storage at two temperatures, but the increases of total phenols and antioxidant capacity at $5^{\circ} \mathrm{C}$ were smaller than those at $15^{\circ} \mathrm{C}$, which may be related to the increase of browning degree after 3 days at $15^{\circ} \mathrm{C}$.

In the storage of potato seedlings, temperature is an important factor, but potato seedlings are affected by various environmental factors. Therefore, different storage methods can be used to compensate for the defects of potato seedlings. Moreover, the increase of antioxidant capacity and material changes in potato seedlings need further theoretical research, which can be better explained by the research on enzyme level and gene level. In future research, the following aspects should also be studied:

(1) The research on the physiological mechanism of potato can be carried out in the seedling stage of potato, and different stages can be set up, such as mature stage, flowering stage, etc.; at the same time, the root, stem, tuber, and other different parts of potato can be carried out, so as to further study the mechanism of high temperature tolerance

(2) The results showed that GRF gene could regulate the growth of potato leaves in two directions, and the function of GRF gene could be further verified. Meanwhile, GRF gene could be expressed and verified in different parts of potato plants

(3) The preliminary screening of Fe SOD gene can further verify its gene function and explore the correlation between SOD gene and potato high temperature

(4) We can use transcription method to find other genes that can coordinate or resist high temperature, and further study them

\section{Data Availability}

The datasets generated during and/or analyzed during the current study are available from the corresponding author on reasonable request.

\section{Conflicts of Interest}

The authors declare that they have no conflicts of interest.

\section{Acknowledgments}

The research was supported by Hebei Province Science \& Technology Pillar Program: Greation of Potatos High-
Quality Germplasm Resources and New Breeding Technique (no. 16227508D), Hebei Province Collaborative Innovation Center of Potato Technology and Emerging Industry.

\section{References}

[1] S. S. Dahham, S. S. Al-Rawi, A. H. Ibrahim, A. S. Abdul Majid, and A. M. S. Abdul Majid, "Antioxidant, anticancer, apoptosis properties and chemical composition of black truffle terfezia claveryi," Saudi Journal of Biological Sciences, vol. 25, no. 8, pp. 1524-1534, 2018.

[2] H. J. Yang, Y. S. Lee, and I. S. Choi, "Comparison of physicochemical properties and antioxidant activities of fermented soybean-based red pepper paste, gochujang, prepared with five different red pepper (Capsicum annuum L.) varieties," Journal of Food Science and Technology, vol. 55, no. 2, pp. 792-801, 2018.

[3] P. Ł. Kowalczewski, A. Olejnik, W. Białas et al., "Effect of thermal processing on antioxidant activity and cytotoxicity of waste potato juice," Open Life Sciences, vol. 14, no. 1, pp. 150-157, 2019.

[4] S. Mazurek, R. Szostak, A. Kita, A. Z. Kucharska, A. SokółŁętowska, and K. Hamouz, "Determination of antioxidant activity and polyphenols content in chips by Raman and IR spectroscopy," Food Analytical Methods, vol. 10, no. 12, pp. 3964-3971, 2017.

[5] E. H. Mervat, A. A. Mohamed, M. Z. Salem, M. S. Abd ElKareem, and H. M. Ali, "Chemical composition, antioxidant capacity and antibacterial activity against some potato bacterial pathogens of fruit extracts from Phytolacca dioica and Ziziphus spina-christi grown in Egypt," Scientia Horticulturae, vol. 233, no. 15, pp. 225-232, 2018.

[6] M. Z. Islam, B.-J. Park, and Y.-T. Lee, "Effect of salinity stress on bioactive compounds and antioxidant activity of wheat microgreen extract under organic cultivation conditions," International Journal of Biological Macromolecules, vol. 140, pp. 631-636, 2019.

[7] A. J. Keutgen, E. Wszelaczyńska, J. Pobereżn et al., “Antioxidant properties of potato tubers (Solanum tuberosum L.) as a consequence of genetic potential and growing conditions," Plos One, vol. 14, no. 9, Article ID e0222976, 2019.

[8] Z. X. Ng and A. N. See, "Effect of in vitro digestion on the total polyphenol and flavonoid, antioxidant activity and carbohydrate hydrolyzing enzymes inhibitory potential of selected functional plant-based foods," Journal of Food Processing and Preservation, vol. 43, no. 4, Article ID e13903, 2019.

[9] K. Dziadek, A. Kopeć, and M. Tabaszewska, "Potential of sweet cherry (Prunus avium L.) by-products: bioactive compounds and antioxidant activity of leaves and petioles," European Food Research and Technology, vol. 245, no. 3, pp. 763-772, 2019.

[10] C. R. Rojas-Padilla, V. J. Vasquez-Villalobos, C. E. Vital et al., "Phenolic compounds in native potato (Solanum tuberosum L.) cooking water, with potential antioxidant activity," Food Science and Technology, vol. 39, no. 1, pp. 66-71, 2019.

[11] C. Huang, M. Yu, M. Yu, L. Sun, N. Qin, and L. Wei, "Physiological responses of sweet potato seedlings under drought-stress conditions with selenium applications," Journal of Agricultural and Crop Research, vol. 8, no. 5, pp. 98-112, 2020.

[12] S. Nakajima, Y. Ogawa, T. Suzuki, and N. Kondo, "Enhanced antioxidant activity in mung bean seedlings grown under slow clinorotation," Microgravity Science and Technology, vol. 31, no. 4, pp. 395-401, 2019. 
[13] R. Jurkow, R. Pokluda, A. Sękara, and A. Kalisz, "Impact of foliar application of some metal nanoparticles on antioxidant system in oakleaf lettuce seedlings," BMC Plant Biology, vol. 20 , no. 1, pp. 1-12, 2020.

[14] I. G. Sergiev, D. A. Todorova, V. K. Gins, S. M. Motyleva, E. M. Gins, and E. A. Moskalev, "Nutritional value of vegetable Amaranthus tricolor L. seedlings grown in Moscow region," RUDN Journal of Agronomy and Animal Industries, vol. 14, no. 3, pp. 225-238, 2019. 